\title{
EL MIEDO AL POPULISTA LATINOAMERICANO DEL SIGLO XXI
}

\author{
Octavio Humberto MORENO VELADOR ${ }^{1}$ \\ Carlos Alberto FIGUEROA IBARRA ${ }^{2}$
}

\section{Resumen}

En este trabajo se presenta una revisión crítica de las perspectivas que conceptualizan al populismo latinoamericano como una amenaza al orden político, social y económico. Haciendo un uso extenso de la categoría que ignora las diferencias entre el populismo clásico y los actuales procesos nacional-populares en Latinoamérica, la literatura antipopulista vulgar ha creado una imagen del populismo como sinónimo de corrupción, demagogia e irresponsabilidad política que se ha extendido socialmente a través de los medios de comunicación masivos. En el plano académico, el populismo es concebido como un estilo de liderazgo y uso del discurso. Sostenemos que para comprender este fenómeno de antipopulismo contemporáneo, es necesario pensarlo a través de la crítica a los principios que sostiene la ideología neoliberal entre ellos el carácter procedimental de la democracia que postula. Estos principios transformados en pensamiento único han convertido al populismo en el gran "otro" de la política latinoamericana. Más aún, en la otredad en la que se ha colocado al populismo subyace la otredad del comunismo construida en el contexto de la guerra fría.

Palabras clave:Miedo, populismo, democracia, neoliberalismo.

\footnotetext{
Abstract

This article presents a critical review about the perspectives that describes Latin American populism as a political, social and economic threat. In an extensive use of the concept of populism, the vulgar anti-populist literature dismisses the differences between the classic populism and the Latin American current national-popular process.

${ }^{1}$ Doctor en sociología, Profesor en la Facultad de Derecho y Ciencias Sociales de la Benemérita Universidad Autónoma de Puebla, México -octaviohmoreno@gmail.com

${ }^{2}$ Doctor en sociología, Profesor-Investigador del Instituto de Ciencias Sociales y Humanidades “Alfonso Vélez Pliego”, Benemérita Universidad Autónoma de Puebla, México -carlosfigueroaibarra@gmail.com 
It has created an image of populism as synonymous of corruption, demagogy and political irresponsibility and this image has been wide spread through the media. In the scholar level, populism has been conceived as leadership style and discursive use. We contend that for the comprehension of the contemporary anti-populism, it is necessary to think about it through the criticism to the principles of the neoliberal ideology, among them the procedural democracy that it defends. These principles transformed in unique thought has converted the populism into the great "other" in the Latin American politics. Even more, the populism "otherness" is based in the otherness of the communism during the cold war.

Keywords: Fear, populism, democracy, neoliberalism.

\section{Résumé}

Ce travail présente une révision critique des perspectives qui conçoivent le populisme latino-américain comme une menace à l'ordre politique, social et économique. Dans une large utilisation du concept qui ignore les différences entre le populisme classique et les processus nationaux-populaires actuels en Amérique Latine, la littérature antipopuliste vulgaire a créé une image du populisme en tant que synonyme de corruption, de démagogie et d'irresponsabilité politique qui s'est étendue socialement à travers les mass-médias.

Sur le plan académique, le populisme est conçu comme un style de leadership et d'usage du discours. Nous soutenons que pour être en mesure de comprendre ce phénomène d'anti-populisme contemporain, une réflexion par le biais d'une critique aux principes de l'idéologie néolibérale, parmi lesquels la démocratie procédurale qu'il postule, s'impose. Ces principes, transformés en une pensée unique, ont fait du populisme le grand Autre de la politique latino-américaine. Encore plus, l'autreté dans laquelle le populisme a été placé est basée dans l'autreté du communisme, construite dans le contexte de la guerre froide.

Mots clés :Peur, populisme, démocratie, néolibéralisme.

\section{Introducción.}

Uno de los principales miedos que se agitan en la política y las sociedades latinoamericanas contemporáneas, es el miedo a lo que en lo que una vertiente de la academia y la propaganda neoliberal se llama "populismo". En lo que se refiere a ésta última, se trata de un miedo que se ha construido desde los medios de comunicación mediante discursos políticos conservadores, que asumen al "populismo" como un fuerte factor de desorden para la política de toda la zona. Esta agitación ha rebasado los órdenes nacionales y se ha colocado en el plano internacional como un discurso que se opone a la búsqueda de políticas alternativas a las que fueron dominantes en la zona principalmente durante los años noventa. Los "populistas" del siglo XXI son calificados como irresponsables al apuntalar propuestas políticas y económicas que van en contra del manejo de la política y la economía dictadas por el neoliberalismo. Se le presenta como un peligro ya que mediante la demagogia y la manipulación política, permiten el 
encumbramiento de liderazgos políticos unipersonales, autoritarios y violentos, que amenazan supuestamente con acabar con los logros de los modelos de representación política producto de las transiciones democráticas de los años ochenta y noventa.

De esta forma, el populismo es nuevamente moneda corriente en el mundo de los debates académicos y políticos en Latinoamerica. Y en esta resemantización de lo populista, populismo termina siendo para muchos sinónimo de corrupción política; de irracionalidad en el manejo de la política económica; de incivilidad al no seguir los caminos políticos de la democracia procedimental; de demagogia al prometer soluciones a problemas para los que la política dominante no tiene solución. El populismo del siglo XXI ha sido convertido en el gran otro de la política latinoamericana, en el villano y la amenaza que supuestamente amenaza a las sociedades latinoamericanas. Sostenemos que en la base de la construcción de esta otredad negativa, particularmente en la propaganda neoliberal, hay atavismos de la guerra fría.

\section{La reformulación conceptual del populismo}

En una obra clásica sobre el tema, Ghita Ionescu y Ernest Gellner (1969) presentaron al populismo como un fantasma que se cernía sobre el mundo, como una ideología que se encontraba fuertemente emparentada con las ideas políticas propias del comunismo y que poco a poco conquistaba espacios en diversas partes del mundo, sobretodo en América Latina. Resulta elocuente que en el mejor estilo de la guerra fría, una obra académica emparentara al populismo con el fantasma del comunismo. Ahora que el fantasma del comunismo ha desaparecido, surge un nuevo fantasma, el del populismo. Este fantasma populista parece haber salido del baúl a donde fue relegado por el triunfo del pensamiento tecnocrático. Para el pensamiento conservador el populismo parecía muerto, con sus liderazgos y amplias movilizaciones sociales que no tienen cabida en los modelos de representación basados en los modelos partidistas tradicionales. Sostenemos que habiendo terminado la guerra fría, el populismo se ha convertido en el nuevo gran "otro" de la política latinoamericana contemporánea, construido literaria y mediáticamente como una gran amenaza que se cierne sobre la zona. Para comprender el auge de los discursos antipopulistas consideramos que es necesario reconocer los cambios en el pensamiento económico y político asociados al neoliberalismo y al procedimentalismo democrático. Estos cambios están vinculados al auge neoliberal de fines de la decada de los setentas y luego al surgimiento a principios del siglo XXI, de los procesos nacional-populares que en diversos países manifestaron una voluntad posneoliberal. Son estos procesos los que generaron en la academia un renovado debate acerca de la naturaleza del populismo y en el terreno de la propaganda neoliberal la construcción de la otredad negativa antes apuntada.

De acuerdo con los aportes de la sociología política latinoamericana clásica, un elemento central de los gobiernos populistas latinoamericanos de mediados del siglo XX fue la implementación de una política económica basada en la Industrialización con Sustitución de Importaciones (ISI), que permitió la industrialización nacional y al crecimiento del mercado interno de consumo, posibilitando la inclusión socioeconómica de grandes agregados populares. Es necesario apuntar que si bien los populismos se adhirieron a la ISI y al desarrollismo, no todos los Estados desarrollistas fueron populistas. En la perspectiva de Octavio Ianni (1975), la ISI fue una política económica que aspiraba a lograr independencia en las economías nacionales respecto del control económico internacional. Dicho modelo gozó de resultados favorables desde los años treinta hasta inicios de la década de los ochenta, un largo período durante el cual países 
como Argentina, México y Brasil crecieron a un promedio anual de 5\%. Sin embargo, en los años ochenta este modelo económico comenzó a colapsar debido a que el proteccionismo no permitió el incremento de la productividad, acarreando efectos de baja en los salarios y la recaudación fiscal. Ambas condiciones hicieron imposible continuar con una economía subsidiada, generando estancamiento e inflación, provocando su derrumbe macroeconómico (Cardoso y Helwege 1992:60-62). A esto hay que agregar que la crisis del desarrollismo latinoamericano se acrecentó con la recesión que provocó el crecimiento estratosférico de la deuda externa.

En estas circunstancias, en numerosos gobiernos nacionales se generó la idea de que los problemas de desigualdad en el ingreso, la provisión de servicios públicos, y en general la política social, no eran factibles de resolver mediante la inversión directa de recursos públicos, y decidieron orientar sus políticas hacia los modelos impulsados por organismos económicos internacionales como el Banco Mundial (BM) y el Fondo Monetario Internacional (FMI). Además, para poder legitimar el abandono del desarrollismo y la adopción del neoliberalismo, la propaganda neoliberal construyó un nuevo concepto de populismo cuyas rasgos esenciales hemos apuntado líneas atrás. La operación ideológica para fundamentar que no había más camino que el neoliberal, se completó poniendo en el mismo saco al desarrollismo y al populismo. Se dio pie a la formación de una imagen sobre el populismo íntimamente relacionada con la debacle económica, la corrupción y el clientelismo político. En esencia se asumió como el problema central del populismo la intención de resolver los problemas de desigualdad mediante el uso de políticas macroeconómicas demasiado expansivas. Políticas que recurrían al "financiamiento deficitario, a los controles garantizados y a descuidar los equilibrios económicos básicos", llevando "casi inevitablemente a grandes crisis macroeconómicas que han acabado por lesionar a los segmentos más pobres de la sociedad" (Dornbusch y Edwards 1992:9).

Conforme el Estado desarrollista sufrió del debilitamiento de sus bases económicas, los problemas para la continuación de su proyecto político se multiplicaron. Los sectores de la economía privada asumieron que el keynesianismo económico había generado demasiadas pérdidas y comenzaron a apelar por un retorno del laissez-faire, el retorno a un capitalismo con menos trabas (Klein 2007:87). Este escenario se presentó en buena parte de los países en los que el populismo y su alianza de clases tiempo atrás se había derrumbado. También en todos los demás, en donde no había habido populismo sino un desenvolvimiento económico desarrollista. Así las cosas, se fue abriendo paso a las transformaciones sociales y económicas propias de la época dominada por el neoliberalismo.

El impulso de las políticas neoliberales tuvo como base la desregulación económica, la privatización de empresas estatales y recortes presupuestales en los servicios sociales, iniciativas que implicaron la pérdida de buena parte del terreno ganado durante largos años por los grupos populares en los populismos y dentro de los modelos nacional-desarrollistas latinoamericanos. Estos cambios en el sistema político y económico se plantearon como "reformas estructurales", impulsando por un lado la creación de un conjunto de instituciones que posibilitaran transiciones políticas hacia democracias centradas en su carácter procedimental, y por otro lado, el impulso a políticas económicas que dejaran atrás los modelos intervencionistas de Estado. 
A la sazón de estas transformaciones, la crítica y evaluación del modelo económico desarrollista emparentado abusivamente con el populismo en América Latina, se hizo con base en los cánones del neoliberalismo y la democracia procedimental, enarbolados como los únicos caminos y las verdades irrefutables para toda aquella sociedad que pretenda lograr el bienestar político y social.

\section{El discurso antipopulista contemporáneo}

Es necesario comenzar esta parte de nuestro trabajo diciendo que es necesario distinguir dos vertientes del discurso antipopulista. Una de ellas es la del antipopulismo vulgar que se expresa en trabajos de difusión y que forman parte de la propaganda neoliberal. ${ }^{3} \mathrm{La}$ otra vertiente es la académica que es mucho más elaborada. En la vertiente del antipopulismo vulgar, encontramos a un autor como Enrique Krauze (2005) quien propuso una serie de rasgos específicos para caracterizar al populista latinoamericano del siglo XXI. Para él, el populismo se resuelve básicamente como la exaltación del líder carismático, la funcionalización de la figura de un líder providencial que "resolverá, de una vez y para siempre, los problemas del pueblo". Un fenómeno que posee un mensaje y estrategia política que tiene como base, y segunda característica principal, a la demagogia como "vehículo específico de su carisma". Un vehículo que le permite "construir" la verdad popular y hacer de ella su vínculo principal con el pueblo. Dicho vínculo, creado de manera arbitraria, poseería la facultad de volverse un tipo de construcción de la realidad, construcción que en la arenga política se convierte en un solo gran núcleo de discurso y de verdad. Característica que sólo revelaría la abominación intrínseca de los populistas hacia la libertad de expresión, y el principio de la secesión dolosa entre el pueblo y el no-pueblo.

Según este autor, en el plano económico el populista también se caracteriza porque "utiliza de modo discrecional los fondos públicos" y no posee "paciencia con las sutilezas de la economía y las finanzas". Se apropia del erario público para enriquecerse e impulsar únicamente aquellos proyectos que "considere importantes o gloriosos, sin tomar en cuenta los costos". Un tipo de ejercicio económico que lo lleva irremediablemente a repartir directamente la riqueza, pero sin considerar más consecuencia que el cobro del favor económico mediante formas corporativas de apoyo político y electoral. En conjunto, tanto las condiciones políticas como las económicas delinean al populista como un agente en extremo peligroso, ya que a través de la repartición económica y su relación cercana con el "pueblo", el populista siempre alienta el "odio de clases". Odio que para este autor es provocado por la demagogia del líder, pero que nunca se debe a la existencia de la inequidad y la injusticia social en aquellos países en donde el "populista" obtiene relevancia. Esta imagen de encono y de movimiento político irracional también se proyecta hacia el orden internacional, cuando en busca de legitimidad o de un manto para encubrir su incapacidad política y económica recurre a crear la imagen de un "enemigo exterior".

\footnotetext{
${ }^{3}$ Una destacada representante del antipopulismo vulgar por la proyección mediática que ha tenido es la politóloga guatemalteca Gloria Álvarez. Su discurso antipopulista ante el Parlamento Iberoamericano de la Juventud, celebrado en 2014 en Zaragoza, España, fue ampliamente reproducido por las redes. A través de youtube se pueden ver repetir hasta la saciedad los argumentos que aquí reseñamos.
} 
Planteado de esta forma, el populismo es un peligro constante, ya que entre su demagogia, los deseos malévolos del líder, y la torpeza de los pueblos arengados por el discurso, la movilización popular siempre acecha como la marea que amenaza con arrancar el statu-quo prevaleciente. Amenaza que según Krauze, se concretiza cuando después de lograr conquistar el poder de Estado, el populista siempre tiende a "despreciar el orden legal" existente y lo sustituye por un orden creado bajo los designios del propio líder. El populismo asume los límites al poder como aristocráticos y "contrarios a la voluntad popular", y por ello, el populista "mina, domina y, en último término, domestica o cancela las instituciones de la democracia liberal". En consecuencia, para este autor existen pocos matices o diferencias entre el autoritarismo (o incluso el totalitarismo) y el populismo. (Krauze, 2005).

La postura antipopulista de Krauze se traduce en una aversión casi personal a los populistas contemporáneos, y tal parece a cualquier personaje que rete los designios del buen pensar dominante. Como muestra de esta tendencia basta recoger algunas de sus palabras:

El populismo es una simplificación de ese complejo mecanismo (checks and balances). Lo que el populista busca - al menos esa ha sido la experiencia latinoamericana- es suprimir en beneficio propio la tensión entre el liderazgo político y la voluntad popular, y nada mejor para lograrlo que establecer un vínculo directo con el pueblo, por encima, al margen o en contra de las instituciones, las libertades y las leyes. La iniciativa, hay que subrayarlo, no parte del pueblo sino del líder carismático (2012: 14-15).

No hay populismo sin la figura del personaje providencial que supuestamente resolverá, de una buena vez y para siempre, los problemas del "pueblo", y lo liberará de la opresión del "no pueblo". (...) El populista se apodera de la palabra y fabrica la verdad oficial. Una vez investido en intérprete predominante o único de la realidad (o en agencia pública de noticias), el populista aspira a encarnar esa verdad total y trascendente que las sociedades no encuentran -aunque a menuda aspiran a ella- en un Estado laico (2012: 15).

Al igual que otros textos de propaganda neoliberal, el sujeto privilegiado de la crítica antipopulista de Krauze, fue Hugo Chávez. Al respecto recogemos algunas palabras vertidas en ocasión de lo que fue su segunda toma de posesión en enero de 2007:

Respaldado por la fuerza de esos 7. 300, 000 "votos bolivarianos", en su discurso inaugural Chávez dio un nuevo salto cualitativo en su simbiosis fidelista y buscó superarla (...) Y dejó entrever "las sorpresitas que les tengo preparadas a mis muy queridos", un conjunto de leyes revolucionarias que implican "una reforma profunda de (...) nuestra Constitución Bolivariana" para lograr el establecimiento definitivo de la "República Socialista de Venezuela". Ante el entusiasmo del graderío que lo interrumpía continuamente con ovaciones y vítores, recurrió a sus queridos 
términos besbolísticos, $\mathrm{y}$, recordando al pitcher zurdo que alguna vez fue, lanzó "una curvita a la esquina de afuera": "todo aquello que fue privatizado, nacionalícese". Luego de ese lanzamiento "bajito, a la rodilla" siguieron otros: "Moral y luces" en la educación popular, una "nueva geometría del poder sobre el mapa nacional", los "Consejos comunales", la conformación del "Estado comunal", del "Estado socialista", del "Estado Bolivariano". En una palabra, se acaba el juego de la democracia y la sociedad abierta (2012: 77)

En el mismo tono de crítica y bajo preceptos muy similares, otros autores se han manifestado en contra de los supuestos líderes populistas y los riesgos que implican para la libertad, ya que desde su perspectiva: "el verdadero progreso es inseparable de una alianza irrompible de dos libertades, la política y la económica, en otras palabras democracia y mercado" (Mendoza, Montaner y Vargas Llosa 2007:9). Así resuelto, para este autor la situación en América Latina sería muy delicada dado que actualmente en la región existiría un retroceso de la democracia y un regreso del populismo más asincrónico: estatista y comunista. Una forma de "idiotez ideológica" que parecería inagotable, "sorda e impenetrable a su propia tiniebla", incapaz de entender los beneficios de la verdadera libertad (Mendoza, Montaner y Vargas Llosa 2007:13).

Lo que resulta interesante de destacar cómo es que la arenga antipopulista en su versión más vulgar -por cierto la más difundida en los medios de comunicación-, es una suerte de reciclaje del anticomunista arsenal discursivo de la guerra fría: libertad y democracia contra autoritarismo y totalitarismo, democracia y mercado contra estatismo y comunismo. El mundo maniqueo de la guerra fría resuena en la argumentación de Krauze, Vargas Llosa y otros autores similares. Independientemente de la poca rigurosidad académica de ambas perspectivas, sus ideas utilizadas como propaganda han terminado por crear miedo y convertirse en un arma política e ideológica. La desaparecida paranoia anticomunista subyace en las alocuciones antipopulistas de carácter propagandístico. No resulta una casualidad que en su trabajo, Krauze al atacar a la "bestia negra" del populismo (Hugo Chávez), invoque a la anterior bestia negra del comunismo (Fidel Castro). Desastre político, inestabilidad económica, corrupción, autoritarismo, caudillismos, tales son los males que se pregonan y que infunden temor en las sociedades ante supuestas regresiones a formas "arcaicas" de dominación política y organización económica propias del supuesto populismo latinoamericano.

En el ámbito ajeno al antipopulismo vulgar, el concepto de populismo ha perdido su relación con la idea de un proyecto de Estado o un tipo de organización política y social ligados a las experiencias de gobierno que empezaron a observarse en la América Latina desde la década de los treinta del siglo XX especialmente en países como México, Argentina y Brasil. Así las cosas, para algunos estudiosos el populismo se puede resumir como un "estilo de liderazgo", un estilo de hacer política que presenta caracteres íntimamente relacionados con la demagogia y lo carismático. Un ejemplo de ello es la propuesta de Freidenberg quién conceptualiza al populismo como un "estilo de liderazgo", una "manera en que el líder se relaciona con los seguidores, el modo en los moviliza o el tipo de discurso que emplea" (Freidenberg 2007:10). Otro ejemplo está presente en las ideas de un autor como Jorge Lazo para quién el caso contemporáneo de Hugo Chávez se puede entender de acuerdo a las "fórmulas populistas clásicas del subcontinente, aparece el líder carismático, paternalista, justificadamente autoritario, el 
alter ego del pueblo, el instrumento mesiánico que libera los poderes míticos de la nación" (Lazo 2002). Este tipo de perspectivas han redundado en una transformación conceptual del populismo que busca reducirlo a un fenómeno exclusivamente determinado por liderazgos demagógicos y corruptos. ${ }^{4}$ De igual manera se han presentado algunos intentos de conceptualización que se concentran en considerar al populismo como una ideología simplista, fundamentada en una visión dicotómica de la sociedad: entre un pueblo puro y una élite corrupta (Mudde 2004: 543 y 2012: 19). No estamos de acuerdo con esta visión del populismo, porque aun cuando éste a menudo hizo uso de liderazgos carismáticos, lo que lo definió como tal fue una nueva forma de relación entre Estado y sociedad nacida de la necesidad de acumular fuerzas políticas para impulsar una modernización capitalista.

Dentro de esta crítica a las perspectivas que asumen al populismo como un fenómeno meramente discursivo debemos considerar a una perspectiva como la de Ernesto Laclau (2005: 27 y 1986: 179-191). A diferencia de los anteriores autores, Laclau no comparte la idea del populismo como una amenaza sino incluso lo ve como un fenómeno progresivo. Pero este se concentra en su dimensión retórica, en su calidad de discurso que "interpela" a los diferentes grupos sociales para entablar organizaciones sociales y políticas amplias. Consideramos que esta interpretación centrada en el discurso priva de su núcleo material al populismo histórico latinoamericano, el cual se encuentra en su propuesta política y económica. El resultado de esta concepción es que para Laclau no hay diferencia entre los populismos clásicos y los procesos nacionalpopulares actuales. Además el concepto de populismo se vuelve una categoría tan laxa que líderes populistas pueden ser desde Carlos Salinas de Gortari (el presidente artífice del neoliberalismo mexicano) hasta Mao Zedong o Fidel Castro. (Laclau, 2005:132155)

Con un discurso parecido al de la propaganda neoliberal, para un autor como José Luis Reyna, argumentando desde la ciencia política, el panorama político en América Latina ante la llegada de los gobiernos de izquierda se debatiría entre la "democracia y el autoritarismo". Existiría una "izquierda moderna y una izquierda populista" ; la primera estaría ejemplificada con un gobierno como el de Michelle Bachelet y la segunda se encontraría representada por Evo Morales "quién al nacionalizar como un acto soberano, evocó a los fantasmas de la izquierda del pasado, la confrontación". En su expresión máxima la izquierda populista tendría a su "su ícono representativo en el mandatario venezolano Hugo Chávez". De acuerdo con Reyna, Chávez "a pesar de que la institución presidencial que ocupa tiene rasgos democráticos, su gobierno es populista” (Reyna 2006:762). De igual manera, para Reyna los llamados gobiernos populistas serían en extremo peligrosos ya que:

...pretenden alterar la trama democrática del sistema político. Que intenten modificar la función de las instituciones democráticas con el fin de encontrar un camino sin obstáculos para ejercer un poder personal omnímodo (...) de esta manera, al alterar el funcionamiento de las

\footnotetext{
${ }^{4}$ Algunos de los autores que han participado también de esta perspectiva son Dahrendorf, 2005: 38; Hermet, 2001 y Loaeza, 2007: 232.

${ }^{5}$ Esta es una visión que sido también suscrita por un autor como Teodoro Petkoff (2005).
} 
instituciones que la democracia ha construido, existe la posibilidad que devengan dictadores o líderes mesiánicos (2006:765).

De acuerdo con esta perspectiva, el pecado fundamental del populismo estaría en faltar a las reglas de la representación política liberal, dado que bajo el uso de la idea de "pueblo", la personalidad individual del "ciudadano-elector" se vería trastocada. Dicha personalidad se vería eliminada de manera expedita ante la presencia de los grandes agregados sociales que se mueven de acuerdo a los dictados perversos del líder.

En este mismo sentido, un filósofo como Ralf Dahrendorf, describe al populismo como un virus que "golpea a las democracias" y que daña por igual a las democracias consolidadas como a las que estarían en proceso de consolidación. Un ejercicio peligroso en donde se discuten las cuestiones importantes con la gente y donde el "pueblo" es instigado demagógicamente (Dahrendorf 2005:38). Ante esta perspectiva, el líder populista sería incapaz de gobernar dado que una vez instalado en el poder, toda la ventaja lograda mediante el discurso se perdería ante el complejo contexto político existente, lo que lo mostraría claramente como mentiroso. De igual forma, el populismo sería únicamente un movimiento de protesta incapaz de avocarse a la acción, dado que sus programas complejos de reforma casi nunca son realizables: "el populismo es simple, la democracia es compleja" (2005:39).

Otra crítica existente actualmente, va en el sentido de señalar a los "populismos contemporáneos" como una formación política "exótica" que cumple únicamente con "satisfacer los deseos iconoclastas de la multitud", tomando prestados puntos del populismo clásico como la defensa de los pobres o el orgullo nacional (Hermet 2001:21). Desde este perspectiva los populismos contemporáneos tendrían características de movimientos "atrapalotodo", los cuales se aprovechan de las frustraciones de obreros, empleados o campesinos, grupos que comparten la "obsesión de ver desaparecer su universo material y cultural bajo el efecto la mundialización y de un hundimiento concomitante de las soberanías nacionales" (Hermet 2001:29). En síntesis, el populismo contemporáneo sería un movimiento político que es en esencia acomodaticio a los problemas de las democracias establecidas y por tanto, demagógico. El populismo aparece nuevamente como un "riesgo para la democracia" en tanto relativiza o abiertamente desprecia a las instituciones y los procedimientos democráticos en boga. Esto sucede porque para la movilización popular, la democracia se presenta como algo que va más allá de las formas meramente procedimentales, situación que interpela directamente a la idea de que la política se sintetiza y realiza en una serie de procedimientos. En consecuencia, las prácticas asociadas a la democracia directa como las consultas o los referéndums atentarían contra el espíritu democrático representativo, supuesto puerto de llegada final y realización máxima de la democracia liberal.

Se ha dicho también que los populistas son invariablemente irresponsables, en tanto sus propuestas políticas son lejanas a la realidad previamente determinada por el dominio de las políticas neoliberales. El populista rompe con la economía política de lo posible, "una economía y una política más preocupadas por la ética de la consecuencia que por la ética de las convicciones", en un contexto moderno en el que las políticas económicas deben ser más pragmáticas y "más atentas a la eficacia que a la integridad ideológica" (Santiso 2001:224). De esta forma para los críticos del populismo las ideas de reforma política y social serían abiertamente irresponsables y fuertemente ideológicas. 
En contraste a la dupla mágica de mercado y democracia procedimental, una propuesta política que busque reformar las estructuras económicas neoliberales y de libre mercado internacional, se transforma en irresponsable y poco racional. Las propuestas de redistribución ampliada de la renta y de rehabilitación de las industrias nacionales hablarían de mentes retrogradas y de corruptelas en puerta, propias de un pasado ya rebasado y por sí mismas insostenibles.

\section{Las razones del antipopulismo del siglo XXI}

Ante la amplitud y variedad de las críticas antipopulistas, un autor como Aibar propuso una categorización históricamente estructurada sobre las impugnaciones hechas al populismo:

- El populismo como obstáculo para la modernización (impugnación que puede denominarse "ilustrada modernizante")

- El populismo como obstáculo para el desarrollo (impugnación "tecnocrática desarrollista")

- El populismo como generador de desorden social y político (impugnación "autoritario organicista")

- El populismo como obstáculo para la implementación del libre mercado (impugnación "liberal económica")

- El populismo como amenaza para la democracia (impugnación "liberal procedimental o institucionalista") (2007:25).

Respecto a la primera crítica del populismo como obstáculo para la modernización, la encontramos en la tradición de pensamiento encabezada en los años sesenta y setenta tanto por Gino Germani (1971) como por Di Tella (1965). Ellos atribuyeron al populismo latinoamericano buena parte de la responsabilidad sobre la imposibilidad de acercar a los países de la zona a la modernidad política inspirada en los modelos europeos de participación y organización política. En cuanto a las siguientes tres críticas al populismo (como proclive al desorden social y político; como retrograda al criticar o ir en contra del libre mercado; como una amenaza para la democracia), son en buena medida las que han dominado las referencias actuales sobre los supuestos populismos existentes. Es posible decir que estos señalamientos han sido ya durante largo tiempo los ejes que han alimentado la crítica y el gran demérito social del que hoy es víctima cualquier movimiento que se le califique como populista. La manipulación y propagación sin reservas de dichas críticas han terminado por demeritar y crear un halo de confusión sobre el significado del propio término. En estas condiciones, parece necesario repensar al populismo de acuerdo a las coordenadas actuales del pensamiento conservador, a fin de entender hasta qué punto pueden ser verídicas, erróneas o mal intencionadas.

Desde nuestra perspectiva, una razón fundamental para que el populismo aparezca como indefinido y preocupante es que en él nunca está dicho todo. Más bien éste se reconstruye de acuerdo al espacio particular donde se desenvuelve. El populismo surge más bien como una respuesta ante los límites que experimenta en su propio medio. Y es precisamente esta situación la que lo hace aparecer como un hoyo negro de la teoría, ya que no existe un referente concreto y definitivo desde donde se le pueda clasificar o entender. En él todo es improvisación y construcción política desde la interpelación. 
Ante este aspecto hemos visto surgir las propuestas que se concentran en los aspectos más subjetivos del fenómeno, ya sean los contenidos propiamente discursivos, los liderazgos o el carisma personal. En principio, tal como nos enseña la sociología clásica latinoamericana, los gobiernos populistas de mediados del siglo XX construyeron su hegemonía con base en la inclusión social y política no solo de los grupos populares, sino también de las clases medias (e incluso de élites), todos coaligados bajo un proyecto nacionalista. Por lo tanto, los populismos no fueron un mero fenómeno discursivo o carismático, sino también fueron materialmente incluyentes en términos sociales y económicos. Acaso los grupos que no fueron integrados, fueron las oligarquías desplazadas y una parte de los intereses capitalistas internacionales aliados con las oligarquías. En este sentido es posible advertir que la adhesión a los populismos se explica mucho mejor por la inclusión material y sociopolítica de los diferentes grupos bajo un proyecto de Estado, que por el encanto abstracto y discursivo de los agregados ciudadanos.

En cuanto a las perspectivas que asumen al populismo como un fenómeno esencialmente antidemocrático consideramos que buena parte de la incomodidad que despierta está en que los procesos que la crítica antipopulista denomina populismos, apelan a un sujeto plural, a un "nosotros" social que difumina la individualidad y abre el camino para el surgimiento de proyectos político-sociales inclusivos, no sólo discursivamente, sino también materialmente. Una expresión social que busca unir lo que el neoliberalismo y las perspectivas políticas y económicas individualistas desunieron, una idea de pueblo, de un nosotros social que protesta y se opone a los proyectos dominantes. En este sentido, consideramos que, en todo caso, la mirada sobre el supuesto populismo contemporáneo debe estar más próxima a considerarlo como un propio "síntoma de la democracia", en el entendido de que éste "funciona como un elemento paradójico que pertenece a la democracia" y que "impide que ésta se cierre como un orden político domesticado o normalizado dentro de procedimientos establecidos, relaciones institucionales, rituales reconfortantes" (Arditti 2010: 147).

Por otro lado, sostenemos que las visiones que asumen a los procesos alternativos en marcha como un peligro para la democracia, ignoran el hecho de que en casos como los de Bolivia, Venezuela y Ecuador, se presenció el derrumbe del sistema de partidos previo a la llegada de los nuevos gobiernos progresistas. Un derrumbe que fue parcialmente propiciado por los movimientos y frentes electorales al triunfar en elecciones, pero que ya desde años antes venían mostrando signos de su agotamiento. Al menos en el caso de Venezuela, su sistema se concebía como un modelo ejemplar de transición democrática en América Latina, un sistema que se mantenía acorde con los criterios políticos de la teoría de la transición democrática, pero que en los hechos se demostró como un sistema fuertemente elitista y muy poco representativo de los intereses populares. Más aún, en el caso de Bolivia la existencia de una representación política indígena directa es un hecho que no puede juzgarse como antidemocrático. Al contrario, la existencia de un movimiento plural y predominantemente indígena como lo es el Movimiento al Socialismo (MAS), la misma presencia de Morales en la presidencia como un directo representante indígena, lo vuelve un fenómeno esencialmente democrático. O bien el caso de Ecuador, en donde la emergencia de una vigorosa actividad de la sociedad civil puso en jaque a los gobiernos establecidos y finalmente impulsó una candidatura ciudadana con el respaldo de numerosas organizaciones populares. 
De manera contraria a lo que se les imputa, los movimientos políticos en cuestión muestran una trayectoria y una perspectiva política distante a la derivada de la satanización neoliberal del "populismo". En todos los casos, estos movimientos han logrado mediante la organización de sus fuerzas sociales, ocupar posiciones de gobierno a través de los cauces electorales-institucionales existentes, siempre desde la vía reformista pacífica e inclusiva.

Sostenemos que la característica central de estos movimientos es el tipo de participación política sobre la que se han construido, ya que esta ha trascendido los límites de la democracia procedimental gracias a la forma de participación política que propician y el tipo de contenidos sociales que los inspiran. Es por ambas razones que estos movimientos contienen formas de acción y organización abiertas, reformulando sus formas de acción política respecto a cómo se conceptualiza tradicionalmente a los contenidos y las plataformas de participación política. La razón principal para postular esto es que desde la participación política popular en los frentes político-sociales organizados, estos movimientos han sido capaces de impulsar políticas que se separan de los cánones de la hegemonía neoliberal y dotan de un sentido político diferente a las políticas nacionales. Aunado a que como grupos de apoyo político estos son frentes multiclasistas que reúnen a una gran cantidad de actores y grupos políticos diferentes, situación diferente a la forma como tradicionalmente se conceptualizaba la revolución al ser de una sola clase social.

\section{$\underline{\text { V. Conclusiones }}$}

Pretendemos haber mostrado las debilidades que poseen las perspectivas contemporáneas antipopulistas y para ello hemos empleado, entre otros elementos, el legado de la sociología clásica latinoamericana. Hemos también planteado que estas perspectivas han surgido como consecuencia de la aparición de procesos políticos de carácter nacional-popular y en general de procesos que en mayor o menor medida tienen una voluntad posneoliberal. Que este hecho ha desencadenado una reacción neoliberal que en su versión más vulgar repite la visión maniquea del anticomunismo de la guerra fría. Resulta curioso que aun algunas de las críticas académicas más sofisticadas al populismo, repiten la contraposición libertad-democracia versus totalitarismoautoritarismo que privó durante la guerra fría. Además, hemos rechazado a las perspectivas que procuran describir o desprestigiar a algunos de los procesos políticos contemporáneos en América Latina como supuestos populismos de acuerdo a la perspectiva conservadora. Cabrá preguntarse entonces si el concepto de populismo elaborado por la sociología latinoamericana clásica no basta para describir estos procesos. Sostenemos que no es así, que lo que sucede es que los fenómenos latinoamericanos que hemos observado recientemente tienen algunas similitudes con los procesos populistas de mediados del siglo XX, pero también son diferentes en aspectos esenciales.

Al igual que en los orígenes del populismo clásico que surgió ante la crisis de los Estados oligárquicos que se observó a partir de la tercera década del siglo XX, esta aparición del fantasma populista obedece a la crisis del modelo político y económico neoliberal. La crisis neoliberal generó un momento en el que los espacios de bienestar y justicia se redujeron drásticamente, causando brotes de movilización popular en busca de cambios en las estructuras de estado. En este sentido, es totalmente errónea la 
conceptualización del supuesto populismo como antidemocrático. Más bien lo que la crítica antipopulista llama "populismo" es un espacio por naturaleza de democracia en tanto se encuentra articulado fuertemente a la llamada "interpelación populardemocrática", es decir, una lucha por la ampliación del espacio de participación popular en la política oficial (Laclau 1977:144).

Visto desde nuestra perspectiva, las experiencias recientes de los movimientos sociales y los gobiernos nacionales que se han derivado de ellos poseen en el centro un conjunto de reivindicaciones sociales producto del gran crecimiento de la desigualdad y la exclusión social. El mote de populistas en este sentido parecería obedecer más a una forma de descalificación hacia quiénes elevan reclamos a sus Estados, una situación que demuestra contradicción en aquellos críticos que se autoproclaman como demócratas y que reniegan a reconocer la legitimidad de las demandas de ciudadanización efectiva y participación política soberana y popular. La crítica antipopulista, sea en su versión académico o en la vulgar, es una reacción contra el desafío al paradigma de la democracia neoliberal. Lo paradójico es que este desafío se ha hecho desde las propias premisas de la democracia liberal.

\section{Al respecto Aibar comenta:}

Cabe preguntarse de que reniegan o de que renegaron quienes han producido las exclusiones: reniegan del sistema de leyes que ellos mismos instauraron. Reniegan, por ejemplo, de la proclamada igualdad ante esas mismas leyes, del alcance universal de éstas, pero también de los imaginarios o utopías que esas leyes pretenden instaurar. En casi todas las constituciones de casi todos los países de Latinoamérica, podemos encontrar proclamaciones de derechos sociales, civiles y políticos que, sistemáticamente, son negados en la práctica por las mismas élites que tuvieron a su cargo la redacción de las mencionadas constituciones (2007:37).

Planteado de esta manera, es posible observar cómo la idea de democracia se ha convertido en un discurso que cumple con relegar a aquellas formas consideradas como impropias, como expresiones que se encuentran fuera del mundo de la razón y la justicia (De la Torre 2007:69). Un discurso maniqueo empleado para excluir y señalar a un otro irracional, una otredad que marca la diferencia entre los verdaderos y los falsos demócratas (Arditi 2004). Esta situación se ve reforzada por la idea de que los populismos en sí mismos son ejemplos de liderazgos demagógicos y que estos liderazgos pesan más que cualquier esfuerzo de estructuración y propuesta política legítima. En el fondo se trata de un malestar provocado por el hecho de que los procesos nacional-populares han amenazado con romper los diques que el modelo procedimental de la democracia representativa garantizaría.

De igual manera se asume que la presencia de los liderazgos demagógicos, implicaría la formación de una densa red corporativa sobre la organización en movimiento destinada a trasladarse a cualquier espacio que pudiera ocupar. Sin embargo, el riesgo de organización corporativa es un mero supuesto, ya que no se ha cumplido en todos los casos ni de igual manera. Más bien en el contexto del neoliberalismo y la democracia procedimental, la corporativización no se ha presentado entre la sociedad civil y las estructuras de estado, sino entre las empresas económicas 
transnacionales y los pocos beneficiados por esta estructura y el poder político que ha terminado por volverse un brazo de los intereses del capitalismo transnacional (Klein 2007). Desconociendo esta situación, aquellos que se declaran abiertamente en contra de los movimientos políticos de convocatoria masiva y popular se inclinan por mantener la colusión existente entre empresarios y políticos profesionales, a favor de mantener el relativo espacio de libertad de acción en el que se benefician las empresas capitalistas en los estados nacionales con débil regulación jurídica.

Ante esta situación, el llamado populismo emerge como un riesgo importante para aquellos que resultan beneficiados de la estructura de poder actual. Para aquellos que ven renacer a un monstruo que parecía haber muerto y desaparecido hacía ya hace algún tiempo. En este contexto es precisamente desde donde se debe pensar qué significa el renacer del monstruo populista, en el medio de la campaña de satanización y estigmatización de la construcción de alternativas y luchas políticas-populares en Latinoamérica. Finalmente el eje central en esta discusión está marcado en buena medida por la hegemonía de la democracia liberal procedimental, en tanto es la forma dominante actualmente sobre la vida política oficial en todos los países de Latinoamérica. Paradoja peculiar ya que precisamente a través de la via democrática procedimental es como los ahora denostados "gobiernos populistas" se han hecho del poder de Estado. Los ejemplos sobran: Luiz Inácio da Silva en Brasil, Néstor Kirchner y Cristina Fernández en Argentina, Evo Morales en Bolivia, Rafael Correa en Ecuador, Hugo Chávez y Nicolás Maduro en Venezuela, Tabaré Vázquez y José Mújica en Uruguay. Todos ellos encabezan en mayor o menor medida, gobiernos que tienen un pie en la organización de movimientos populares que rebasan en muchos casos los límites partidarios.

La paradoja en este sentido es que los propios movimientos han excedido los límites que la democracia procedimental les ha marcado. Y en los casos en que han podido aprovechar esta vía para tomar el poder de Estado de manera legítima, han asumido el proyecto de transformarla. De esta forma las críticas que se les han dirigido desde la perspectiva de la democracia procedimental no han hecho más que demostrar las limitantes del propio modelo procedimental: el populismo se ha vuelto el espejo en el que el modelo procedimental se ve reflejado y se niega a mirar, convirtiéndose en la contraparte necesaria de los pendientes que su acción como modelo de organización política y social han provocado. Los movimientos político-populares han terminado por tomar los "daños" causados por el neoliberalismo y los han encauzado a través de un vertedero común, que los vuelve tanto una bandera de movilización como el fundamento de un proyecto político y social que respalda su aspiración a transformar el poder de estado y sus estructuras predominantes. Estos movimientos no han desconocido las potencialidades del reconocimiento de derechos políticos, pero sobrepasan los límites de la democracia procedimental al avocarse al empoderamiento social. No sólo para poder elegir a sus gobernantes como lo marca la democracia procedimental, sino en pos de asumir la construcción de una democracia social que implica para las mayorías la participación en las decisiones que afectan las condiciones fundamentales de su vida. 


\section{$\underline{\text { V. Bibliografía }}$}

Aibar, Julio. (2007). "La miopía del procedimentalismo y la presentación populista del daño" Pp. 19-53 en Vox Populi. Populismo y democracia en América Latina. Julio Aibar Gaete (coord.). Flacso México. México, D.F.

Arditi, Benjamin. (2004). "El populismo como periferia interna de la política democrática" Pp. 63-80 en e-l@tina. Revista electrónica de estudios latinoamericanos. Volumen 2, $\mathrm{N}^{\mathrm{o}}$ 6, Facultad de Ciencias Sociales. Universidad de Buenos Aires. Argentina.

Arditti, Benjamin. (2010). La política en los bordes del liberalismo. Diferencia, populismo, revolución, emancipación. México, D.F.: Editorial Gedisa.

Cardoso, Eliana y Ann Helwege. (1992). "El populismo, el despilfarro y la redistribución" Pp. 58-94 en Macroeconomía del populismo. Fondo de Cultura Económica. México, D. F.

Dahrendorf, Ralf. (2005). "Sobre el populismo ocho observaciones" Pp. 37-41 en Metapolítica. Vol. 9, Núm. 44, noviembre-diciembre de 2005. México.

De la Torre, Carlos. (2007). "Es el populismo la forma constitutiva de la democracia en América Latina" Pp, 55-81 en Vox Populi. Populismo y democracia en América Latina, Julio Aibar Gaete (coord.). Flacso México. México, D.F.

Di Tella, Torcuato. (1965). "Populismo y Reforma en América Latina" Pp. 391-425 en Desarrollo Económico. Revista de Ciencias Sociales. abril-junio 1965 Vol. 4 núm. 16. Argentina. Buenos Aires.

Freidenberg, Flavia. (2007). La tentación populista: una vía al poder en América Latina. Edit. Síntesis S. A. Madrid, España.

Germani, Gino. (1971). Sociología de la modernización. Editorial Paidós. Buenos Aires, Argentina.

Hermet, Guy. (2001). Del populismo de los antiguos al populismo de los modernos. Guy Hermet, Soledad Loaeza, Jean Francois Prud'Homme (comps.). El Colegio de México. México, D.F.

Ianni, Octavio. (1975). La formación del Estado Populista en América Latina. Serie Popular Era. México, D.F.

Ionescu, Ghita y Ernest Gellner (comps.). (1969). Populismos. Sus significados y características nacionales. Amorrortu. Buenos Aires.

Klein, Naomi. (2007). La Doctrina del Shock. El auge del capitalismo del desastre. Ediciones Paidós Ibérica. España, Barcelona. 
Krauze, Enrique. (2005). "El decálogo del populismo iberoamericano" en El País $\begin{array}{llllll}\text { obtenido } & \text { el } & 14 & \text { de } & \text { octubre } & \text { de }\end{array}$ http://elpais.com/diario/2005/10/14/opinion/1129240807_850215.html

Krauze, Enrique. (2010). El poder y el delirio. Tusquets editores. México.

Krauze, Enrique. (2012). “ABC del populismo” Pp. 14-20 en Letras Libres. Abril 2012, Núm. 160, Año XIV. México, D.F.

Laclau, Ernesto. (1977). Política e ideología en la teoría marxista. Editorial Siglo XXI. México. D. F.

Laclau, Ernesto. (2005). La razón populista. Fondo de Cultura Económica. Buenos Aires, Argentina.

Lazo, Jorge. (2002). "Una vuelta al populismo clásico: el caso de Hugo Chávez Frías" en Dimensión Antropológica. Revista Cuatrimestral. Instituto Nacional de Antropología e Historia. Año 9. vol. 24. enero-abril. México.

Loaeza, Soledad. (2007). "La presidencia constitucional y la izquierda en el México post-autoritario" en Izquierda, democracia y crisis política en México Bartra, Roger (comp.). Nuevo Horizonte Editores. México, D.F.

Mendoza, Plinio Apuleyo, Carlos Alberto Montaner y Álvaro Vargas Llosa (2007), El regreso del idiota, Random House Mondadori, México, D.F.

Mudde, Cas. (2004). "The Populist Zeitgeist" en Government and Oposition. Vol 39. Pp. 542-563.

Mudde, Cas. (2012). "Reflexiones sobre un concepto y su uso" Pp. 16-20 en Letras Libres. $\mathrm{N}^{\circ} 160$. Editorial Vuelta. México, D.F.

Petkoff, Teodoro. (2005). "Las dos izquierdas" en Revista Nueva Sociedad. Núm. 197, Mayo-Junio, 2005, Buenos Aires, Argentina. http://www.nuso.org/upload/articulos/3263 1.pdf

Reyna, José Luis. (2006). “América Latina: Hacia una nueva geometría política” Pp. 757-771 en Estudios Sociológicos. septiembre-diciembre, año/vol. XXIV, número 003. El Colegio de México, Distrito Federal, México.

Santiso, Javier. (2001). “Del buen revolucionario al buen liberal?” Pp. 215-250 en Del populismo de los antiguos al populismo de los modernos, comp. Guy Hermet, Soledad Loaeza, Jean Francois Prud'homme. El Colegio de México. Centro de Estudios Internacionales. México, D. F. 